\title{
Reflexiones acerca de la visión del hombre en el judaísmo
}

Reflections about the vision of man in Judaism

Ana María Tapia Adler amtuch@u.uchile.cl Universidad de Chile

Chile

\section{Resumen}

El presente escrito tiene como misión presentar algunos tópicos relacionados con la visión del hombre en el judaísmo, su naturaleza, su origen y su libre albedrio.

Palabras claves: judaísmo, Génesis, hombre, nefesh, ruaj.

\begin{abstract}
The present paper has the mission to present some topics related to the man in Judaism, its nature, its origin and his free will.
\end{abstract}

Keywords: Judaism, Genesis, man, nefesh, ruaj, free will.

\section{Introducción}

A modo de introducción parece necesario, antes de iniciar el tema, aclarar ciertos puntos que considero de importancia.

El primero de ellos es señalar qué entendemos por judaísmo, tarea no exenta de dificultad ya que el judaísmo es complejo: no puede entendérselo solamente dentro de un contexto religioso. El judaísmo es más que una religión, constituye un sistema que regula todas y 
cada una de las fases de la vida cotidiana en base a la Revelación que le fuera dada a Moisés en el Monte Sinaí.

Esta Revelación se encuentra contenida en la Torá (Pentateuco), la que es considerada una enseñanza de vida que enseña al judío cómo vivir esa vida. La Torá, a lo largo del tiempo, ha sido interpretada a la luz de la tradición oral, compilada más tarde en el Talmud, el que es el encargado de explicar y reglamentar todos los aspectos de la vida diaria con la finalidad de no transgredir 'la Enseñanza'.

Mordejai Kaplan (1935) definió el judaísmo, como una civilización y, como tal, en la medida en que surgen nuevas necesidades no solo se transmite, sino que además se transforma. Lo que implica que no debe ni puede mantenerse anclado en el pasado, debe evolucionar para afrontar el desafío del futuro. No es ni ha sido monolítico, fe de ello es la presencia de las distintas corrientes existentes en su interior.

Así, pues, el judaísmo y la cultura judía son entendibles a la luz de la historia del pueblo judío y para conocer esta historia, hay que adentrarse en la lectura de la Torá (Pentateuco), como primera instancia, pues es de allí desde donde emerge la concepción judía del hombre, del mundo y de Dios. Es allí donde encontramos esa visión de mundo y donde podemos encontrar respuesta al tema que hoy presentamos.

El segundo punto importante, es dejar en claro que no puede "darse recetas" o “definiciones" tajantes, porque aun cuando algunos piensen lo contrario, en el judaísmo nadie puede decir kaavlú datí (aceptad mi punto de vista) lo que demuestra que el judaísmo no es ni cerrado, ni rígido ni monolítico. Existe en él una riqueza incomparable, una apertura a todos y cada uno de los aspectos de la vida y del conocimiento. Ello explicaría el por qué continúa vivo y vigente.

En el judaísmo todo es analizable, ningún texto permanece inmune al análisis crítico. Es más, toda averiguación prosigue hasta que puedan tomarse ciertas decisiones o llegarse a la solución de la dificultad. Si no, basta con adentrarse un poco en las aguas de la literatura talmúdica. 
Esa es la razón por la que es importante señalar este asunto y agregar que lo que expongo a continuación es mi propia percepción producto de lecturas sobre el tema. Por ende, pueden existir otros puntos de vista los que, no necesariamente, tienen que estar de acuerdo con el que aquí se presenta.

Hechas estas observaciones que me parecían preliminares y de importancia, podemos adentrarnos al tema mismo.

\section{I}

En el $\mathrm{TaNaJ}^{1}$, la idea de hombre se expresa a través de variados términos que reflejan los diversos aspectos de su naturaleza: las más importantes entre ellas, son: $\mathbf{A d a m}^{2}, \mathbf{I s h}^{3}$, Guever $^{4}$ y Enosh $^{5}$.

Veamos el significado de cada uno de ellos: Adam es un término colectivo, que significa hombre, ser humano, por lo tanto, tiene el significado más amplio de Humanidad; Ish es traducido como "individuo" y utilizado también frecuentemente en sentido colectivo. En el texto de 1 Samuel cap. 23:3 tiene significado de "soldado" o "siervo", hombre de Dios; Enosh, por su parte, es la representación de un colectivo, denota la raza humana aun cuando, ocasionalmente, es usado también para individuos. y, finalmente, Guéver es una palabra que denota al joven adulto y en su sentido más estricto pareciera tener la connotación de "fuerte, poderoso".

El hombre es concebido como un individuo, que puede ser fuerte y débil, miembro de la raza humana y también parte de una unidad familiar.

1 TaNaj es el nombre que se le da al texto masorético (tradicional)hebreo, el término se compone de las primeras letras de las distintas partes que lo forman: T de Torá (Pentateuco), $\mathbf{N}$ de Neviim (Profetas) y K de Ketuvim (Hagiógrafos). Es importante señalar que se corresponde con el denominado Antiguo Testamento de la Biblia utilizada por los protestantes que se diferencia del corpus utilizado por los católicos que agrega textos al canon ya señalado.

${ }^{2}$ Gen 2:7

${ }^{3}$ El término aparece por primera vez en Gen. 2:3 Ishá (de ish),ish aparece en gen 13:16

4 Término aparece en plural en Éxodo 10: 11. No será así; id ahora vosotros los varones, y servid a Jehová, pues esto es lo que vosotros pedisteis...

5 Mencionado en Isaías 56:2. 
Este ser tiene, interiormente, elementos relacionados con su personalidad a los que se denominan: Nefesh, neshamá ${ }^{6}, \mathbf{r u a j}^{7}$, . Nefesh Alma, denota la esencia de toda criatura viviente, es el equivalente de "individuo”, “persona; Ru'aj, “espíritu”, aun cuando difiere con nefesh, muchas veces son considerados como sinónimos. Este término se aplica al poder y la energía que impulsa al hombre en la búsqueda de una vida más elevada. Neshamá, por su lado, equivale a "aliento", el elemento vital que Dios insufló al hombre el espíritu divino.

El hombre está formado por carne y espíritu o alma y conforman ambos una unidad indisoluble. Es decir, es parte de la naturaleza, pero posee atributos de excepción que lo elevan por sobre ella. Ello significa que en contraste con los aspectos espirituales en su naturaleza el hombre posee naturaleza física, basar, $y$, en este aspecto resume o simboliza la fragilidad humana. Posee órganos internos que, desde una perspectiva diferente, se les considera el asiento de ciertas características de la personalidad y la psiquis. Por ejemplo, al corazón (lev)se le considera el centro del pensamiento, la conciencia y la emoción; las venas (klayot) son la fuente de la emoción y de la conciencia; los intestinos (me'ayim), son el asiento de los más poderosos sentimientos y el hígado (kaved) es la capacidad ejecutiva, el "ser".

Estos términos, unidos a otros forman parte de un total más complejo que debería verse dentro de un contexto que nos permiten señalar lo complejo de la personalidad humana.

\section{II}

Es posible que el relato de la creación del hombre sea la clave para abordar el origen del mundo. Por ello nos concentraremos en el Séfer Bereshit (libro de Génesis).

Entonces dijo Dios: Hagamos al hombre a nuestra imagen, conforme a nuestra semejanza; y señoree en los peces del mar, en las aves de los cielos,

6 Nefesh y neshamá aparecen en Génesis 2,7; Entonces Jehová Dios formó al hombre del polvo de la tierra, y sopló en su nariz aliento de vida, y fue el hombre un ser viviente.

7 Génesis 6,17 
en las bestias, en toda la tierra, y en todo animal que se arrastra sobre la tierra".

Y creó Dios al hombre a su imagen, a imagen de Dios lo creó; varón y hembra los creó.”. (Gen 1:26-7)

Hay un segundo texto bíblico que habla de la creación del hombre, se encuentra en el $2^{\circ}$ capítulo del Génesis, versículo 7:

Entonces Dios formó al hombre del polvo de la tierra, y sopló en su nariz aliento de vida, y fue el hombre un ser viviente...

La lectura simple de los textos anteriores nos enseña que el hombre no es un descendiente de Dios ni tampoco es producto de las fuerzas ciegas de la naturaleza. Ha sido creado a propósito y con un propósito, utilizando dos elementos: un cuerpo inanimado creado de tierra y un hálito divino, ambos forman una unidad multifacética que hacen de ella un nefesh jayá, una persona viva, de la que descenderá la humanidad. Si leemos bien, el hombre es único, por ende, así lo es cada ser humano: único.

De allí se desprende que la humanidad -pese a su diversidad- es, esencialmente, una sola familia y que no hay diferencias que hagan que un determinado pueblo, raza o religión sea mejor que otra.

Para $\mathrm{Su}$ creación Dios había concebido un plan: el mundo estaba destinado a ser una creación pacífica, armónica y comprensiva, donde el hombre al igual que otros seres vivos no debía destruir a sus semejantes ni siquiera por necesidad de alimento.

El hombre, es creado el sexto día, el mismo día en que lo fueron los animales mayores. No obstante, es un producto mucho más elaborado, presentado como la cumbre de la creación, formado por una resolución especial y de un modo único: fue hecho a "imagen y semejanza de Dios" lo que le imprime una dignidad única.

Volvamos al texto: 
E hizo Dios animales de la tierra según su género, y ganado según su especie y todo animal que se arrastra sobre la tierra según su especie. Y vio Dios que era bueno.

Y creó Dios al hombre a su imagen, a imagen de Dios los creó: varón y hembra los creó.

$Y$ los bendijo Dios y les dijo: fructificad y multiplicaos, llenad la tierra y sojuzgadla y señoread en los peces del mar, en las aves de los cielos, y en todas las bestias que se mueven sobre la tierra. (Gen. 1:25-28)

Dios entregó un marco natural que define a cada ser. Hay una estratificación en orden ascendente: tierra, vegetales, animales, hombre. La frontera de lo vegetal está entre la tierra y los animales; la frontera de lo animal está entre lo vegetal y el hombre. ¿Dónde está la frontera del hombre?

Pareciera ser, a simple vista, que dicha frontera o no existe o por lo menos queda indefinida. Sus bases son firmes e irrevocables: tierra, vegetales, animales. El hombre es una criatura abierta y ese seria el origen esencial de su libertad". El hombre nace como cualquier criatura, pero en el camino debe "hacerse", es un trabajo permanente, que requiere de trabajo día a día.

El hombre es especial, tanto que el salmista se pregunta:

Cuando veo tus cielos, obra de tus dedos,

La luna y las estrellas que tú formaste,

Digo: ¿Qué es el hombre, para que tengas de él memoria,

¿Y el hijo del hombre, para que lo visites?

Le has hecho poco menor que los ángeles,

Y lo coronaste de gloria y de honra.

Le hiciste señorear sobre las obras de tus manos;

Todo lo pusiste debajo de sus pies (Sal 8: 3-6) 
¡Menudo problema! porque el hombre que está entre el polvo y Dios ha sido puesto como responsable por las obras de Dios.

Este ser que ha sido puesto por responsable de la creación pertenece a una escala natural, proviene del reino animal, terrenal y es dentro de ese reino y ese mundo que ha de realizar su esencia.

Sin embargo, este ser posee un aditamento muy especial, ha sido hecho a imagen y semejanza de Dios. Y como función se le ha impuesto conquistar, dominar, rasgos que no aparecen en la creación de los seres antecedentes.

Por un lado, el hombre es igual que los animales y, por el otro, es diferente de ellos. Es igual porque pertenece a la naturaleza, tiene dentro de sí su simiente, debe reproducirse y alimentarse. Es diferente porque le corresponde ocupar un lugar superior, un lugar de dominio y de conquista. Es el dueño del mundo. Es decir, debe ser el más responsable porque el que constituya la categoría suprema no significa que sea el más privilegiado, sino que es de quien hemos de exigir más.

En su naturaleza física se evidencia que Dios está presente en su gestación y en la preservación del embrión, en la exquisita y amorosa solicitud en su creación. Por ejemplo, cada cabello de la cabeza del hombre proviene de una raíz diferente.

\section{"Hagamos al hombre” dijo Dios.}

¿Con quién habló Dios? ¿A quién le dijo hagamos? Existen dos versiones de este mismo hecho:

Según un midrash Dios habría hablado con los ángeles para consultarlos sobre el proyecto de crear al hombre. Los ángeles debatieron el tema, la opinión estuvo dividida: algunos sostuvieron que no valía la pena formar al "hombre", porque seria una criatura que sólo traería problemas al mundo, y que sería mejor no hacerlo. Los defensores de la creación humana opinaron que, después de todo, también habría entre ellos hombres puros y justos y 
genios altruistas. Finalmente, decidieron a favor de su creación y entonces fue cuando dijo Dios: ¡Hagamos! ${ }^{8}$

También podría decirse que Dios creó al hombre porque no quedó satisfecho ni con los ángeles ni con los animales. Los animales carecían de la buena inclinación y los ángeles eran incapaces del mal. Entonces, Dios creó al hombre y de allí que su origen sea ambivalente.

Esta ambivalencia moral deriva de dos inclinaciones: el yetzer tov (inclinación al bien), que viene del alma y el yetzer hará (inclinación al mal), que viene del cuerpo.

Rab Weissman (2001) escribe

Hashem describió al hombre en diferentes términos que todas las demás criaturas. Él dijo: "Hagamos al ser humano a nuestra imagen, como a nuestra apariencia". Poseerá el intelecto necesario para comprender la Creación y servir al Amo del Universo como uno de los ángeles. Su mente lo distinguirá como ser humano. Hashem añadió - "Si cumple con mi voluntad portará la imagen de D's (sic) y dominará a los animales. De no ser así, perderá su imagen Divina y los animales lo dominaran". 9

\section{III.}

¿Qué significa que el hombre fue creado 'a imagen de Dios'? Para saberlo es menester hablar de Dios.

De acuerdo al Libro de Bereshit (Génesis), Dios es Creador y como tal da forma, organiza, ordena, disipa el caos, impone luz, constituye la armonía y otorga a cada ser su lugar.

Dios hace, contempla, evalúa. Su objetivo es lograr lo bueno. Y, para Él lo 'bueno’ es lo que concuerda con su intención, con su planificación creadora. 'Bueno' es el orden

\footnotetext{
${ }^{8}$ El Midrash dice: Libro de Génesis, p.22

9 Ídem p. 23
} 
cósmico, la creación en etapas que es evaluada en cada una de ellas y que permite que se sostengan mutuamente.

Este Creador, da libertad a su criatura, no la tiene sujeta por su voluntad porque todo ser debe realizar su esencia en libertad. Ser como Dios implica, pues, ser creador, creativo y el hombre lo es cuando Dios lo convoca para que dé nombre a las cosas, para que interprete y le dé sentido a la creación. Dar sentido es tomar conciencia del mundo circundante. Es participar, ser parte, actuar.

Dios formó, pues, de la tierra toda bestia del campo, y toda ave de los cielos, y las trajo a Adán para que viese cómo las había de llamar; y todo lo que Adán llamó a los animales vivientes, ese es su nombre. Y puso Adán nombre a toda bestia y ave de los cielos y a todo ganado del campo; más para Adán no se halló ayuda idónea para él. (Gen 2:19-20)

El hombre entonces, da nombres, define, reconoce, circunscribe al mundo que lo rodea y al hacerlo crea en segunda instancia. El hombre es creador, pero al igual que Dios debe ser creador responsable, debe comprometerse con sus realizaciones. El hombre sólo será imagen y semejanza en el momento en que realice, concretice su idea. A él se le juzgará no por sus ideas, sino por sus realizaciones.

La concepción de hombre es el de un ser creado a imagen y semejanza de Dios, imagen que se traduce en términos de acción, vida, creatividad y libertad.

Porque Dios es libertad creadora, su criatura hecha a imagen y semejanza de El debe dársele también libertad creadora. Por ello la libertad es un rasgo propio de la personalidad del hombre desde el momento de la creación.

La libertad o el libre albedrío es otro de los aspectos de la divina imagen de Dios reflejada en el hombre. Dios dio al hombre la libertad de la elección moral. El hombre puede obedecer o desobedecer a su Creador. El libre albedrío fue el regalo más grande que recibió 
el hombre y la consecuencia de hacer uso de esta libertad fue desastrosa: el hombre se rebeló contra su Creador e introdujo desarmonía en la armonía universal.

Si el primer capítulo de Génesis culmina con el puesto del hombre en el cosmos, en una situación que le permite dominar, conquistar, señorear sobre la creación. "Señorear" no en el sentido de aprovecharse sino en el ser un guardián, un protector de la naturaleza puesta a su disposición. El segundo comienza con el Shabbat, pertenece al orden de la creación y nos introduce específicamente a su vida y analiza en qué consiste su existencia. Su entorno depende de factores ajenos a él y de factores personales ligados a él. Por ejemplo, si no hay lluvia no puede crecer hierba. Pero si llueve y no hay hombre, las hierbas y los vegetales crecerán caóticamente.

¿Cómo se concilian las descripciones del primer y segundo capítulo?

En el primer capítulo era 'varón y hembra', ser humano, que recién aparece en la escena, Dios lo colocó en el Huerto del Edén, un lugar paradisíaco, donde "Dios hizo crecer de la tierra todo árbol deseable a la vista y bueno para comer" (Génesis 2:9) El hombre está contento, allí el hombre se encuentra con un mundo que él empieza a clasificar, a calificar, denominar, ordenar. Pero le falta algo.:

En el segundo capítulo sigue siendo el mismo hombre, pero con necesidades y triste porque no encontró ayuda idónea para él.

“Dijo Dios: No es bueno que el hombre este solo, le haré una ayuda frente a él'. (Gen. 2,18)

Entonces Dios hizo caer sueño profundo sobre Adán, y mientras éste dormía, tomó una de sus costillas, y cerró la carne en su lugar.

$Y$ de la costilla que Jehová Dios tomó del hombre, hizo una mujer, y la trajo al hombre.

Dijo entonces Adán: Esto es ahora hueso de mis huesos y carne de mi carne; ésta será llamada Varona, porque del varón fue tomada. (Gen. 2: 21-23) 
Adam le da un nombre genérico: ishá (varona) mujer, porque de varón (ish) fue tomada. Ambos habitan en el Jardín del Edén donde nada les falta, todas sus necesidades estaban cubiertas. Sin embargo, sobre ellos pesa la orden que Dios le diera a Adam con anterioridad:

De todo árbol del huerto podrás comer; más del árbol de la ciencia del bien y del mal no comerás; porque el día que de él comieres, ciertamente morirás. (Gen. 2:16-17)

La mujer no hizo caso de la prohibición e involucró al hombre. Hizo uso de su libertad, el yetzer hará (inclinación al mal) venció al yetzer hatov (inclinación al bien). La serpiente fue astuta, la convenció y ella comió y dio de comer a Adam. ¿Desobedecieron? No.

Dios llamó al hombre, y le dijo: ¿Dónde estás tú?

Y él respondió: Oí tu voz en el huerto, y tuve miedo, porque estaba desnudo; y me escondí.

Y Dios le dijo: ¿Quién te enseñó que estabas desnudo? ¿Has comido del árbol de que yo te mandé no comieses?

Y el hombre respondió: La mujer que me diste por compañera me dio del árbol, y yo comí. Entonces Dios dijo a la mujer: ¿Qué es lo que has hecho? Y dijo la mujer: La serpiente me engañó, y comí. (Gen. 3:10-13)

Adam y Eva podían rebelarse ante una orden, eran libres de aceptarla o rechazarla. El problema fue otro: Cuando Dios les llamó, se escondieron y al ser interpelados no aceptaron la responsabilidad de su acto. La libertad exige responsabilidad, se es libre por y para algo. El TaNaJ abunda en ejemplos. Citaremos solo dos: la experiencia de Abraham y Moisés.

Abraham reconoce y acepta su libertad. Decidió rechazar los ídolos. Moisés, libremente se identificó con el destino de un pueblo y, al hacerlo, encarnó simbólicamente la aspiración de redención de toda la humanidad 
Para el judaísmo la vida es un esfuerzo de constante elección y compromiso a partir del pacto en el Sinaí y del código de comportamiento que ello conlleva.

¿Puede el hombre ser libre, actuar como tal ante un Dios omnipotente?

En el TaNaJ es posible encontrar textos que niegan la libre elección ${ }^{10}$, pero son casos aislados, las principales corrientes judías apoyan el concepto de la libre elección basándose en el mismo texto bíblico ${ }^{11}$ porque... si el hombre no tiene libertad para elegir, las mizvot (preceptos) no tendrían razón de ser.

Debemos aceptar que, por un lado, existe un Dios omnipotente y omnisciente que sabe todo lo que ha ocurrido y lo que ocurrirá. Por el otro, se nos dice que el hombre es libre. Vale preguntarse ¿en qué sentido el hombre es libre para elegir entre las posibilidades existentes en el universo?

La respuesta a esta pregunta no parece fácil. Podemos decir que cuando Dios otorgó libre albedrio al hombre se autolimitó y, al hacerlo, no puede intervenir sin poner en peligro la totalidad de su creación.

Una de las preguntas de Pirké Avot, (Tratado talmúdico traducido como la Sabiduría de los Padres) demanda: sabe de dónde has venido, hacia dónde vas y ante Quien habrás de rendir cuenta ${ }^{12}$

Esta pregunta está dirigida a resaltar que la finalidad primaria es demostrar que ni el origen del hombre ni su meta biológica forman parte esencial del ser. Esta vida ha sido entregada al hombre para que haga algo con ella, algo que tendrá que ser presentado ante Alguien y recién entonces recibirá su verdadero valor.

\footnotetext{
${ }^{10}$ Por ejemplo en Éxodo 7:3 dice que " Dios endureció el corazón del faraón. En Deut 2:30 se lee "Mas Sehón rey de Hesbón no quiso que pasásemos por el territorio suyo; porque Jehová tu Dios había endurecido su espíritu, y obstinado su corazón para entregarlo en tu mano, como hasta hoy. En ambos textos, el protagonista fue privado de su libre albedrío y debió actuar conforme a una fuerza exterior.

${ }^{11}$ Ejemplos de lo dicho: He aquí que os he puesto delante la vida y la muerte, escoged pues la vida. (Deut 30,19); Él ha puesto delante tuyo fuego y agua. Extiende tu mano hacia lo que deseas. (Ben Siraj 15 :16). También, si buscamos, encontraremos en el Talmud, p.e. - Rab Janina dice: Todo está en poder de los cielos, salvo la reverencia a los mismos (Tratado de Berakhot 331)
} 
Hay una dimensión que no puede soslayarse y es que el mundo tiene dueño. El texto bíblico lo dice claramente: En el comienzo creó Dios... (Gen 1:1).

Así es, Génesis lo dice explícitamente, no pretende enseñar cómo ni de qué manera se hizo el mundo sino más bien decirnos que el mundo se hizo de acuerdo a una voluntad creadora, programada, dueña de toda existencia. Y, si el mundo tiene dueño, significa que tiene Juez. Un juez que, al final, pedirá cuentas a su criatura.

Víctor Frankl (1991) el creador de la logoterapia, sobrevivió a los campos de concentración y a partir de esa abismal experiencia aprendió a vivir y a ayudar a vivir. En su obra El hombre en busca de sentido, escribe:

"El ser humano no es una cosa más entre otras cosas; las cosas se determinan unas a las otras; pero el hombre, en última instancia, es su propio determinante. Lo que llegue a ser-dentro de los límites de sus facultades y de su entorno- lo tiene que hacer por si mismo. En los campos de concentración, por ejemplo, en aquel laboratorio vivo, en aquel banco de pruebas, observábamos, éramos testigos de que algunos de nuestros camaradas actuaban como cerdos mientras que otros se comportaban como santos. El hombre tiene dentro de sí ambas potencias; de sus decisiones y no de sus condiciones depende de cuál de ellas se manifieste.

Nuestra generación es realista, pues dice que hemos llegado a saber realmente lo que es el hombre. Después de todo, el hombre es ese ser que ha inventado las cámaras de gas de Auschwitz, pero también es el ser que ha entrado en esas cámaras con la cabeza erguida y el Shemá Israel, o el Padre nuestro en sus labios". (pág. 74)

\section{IV.}

\footnotetext{
12 Pirke Avot, Perek III, mishna1 en Ética del Sinaí, tomo 2 pág.267.
} 
Entonces dijo Dios: Hagamos al hombre (Gen.1:26), frase que podría leerse como Vaiomer Adonai: Naasé, adam. (Hagamos, hombre) es decir, Dios convoca a ese ser que creó del polvo y al que le insufló aliento de vida, para que hagan algo juntos: "Ven, hagamos, juntos, Tu y yo." El hombre, ente formado de lodo y hálito divino, nace, pero su progreso depende de su libertad y de la sociedad que ha formado con su Creador. Insistimos: Aunque el hombre no es Dios puede ser como Dios, mediante el pleno desarrollo de su potencialidad creadora.

Ser como Dios es ser libre como hombre y entender la libertad en su justo sentido. Es decir, una libertad ajustada a determinados valores que se encuentran contenidos en la Torá.

\section{Bibliografía}

La Biblia, versión Reyna y Valera 1960. En https://www.biblegateway.com ,consulta: Junio 25, 2016.

Barylko, J. (1977). Introducción al judaísmo. Buenos Aires. Fleishman \& Fischbein.

Bunim, I. (1989) Etica del Sinai. Buenos Aires. Edirial Yehud,

Enciclopaedia Judaica. (1981) Jerusalem: Keter Publ. House.

Frankl, Victor. (1981) El hombre en busca de sentido. Barcelona: Heder

Kaplan, Mordejai Judaísm as civilization. 1957 publicado por Tomas Yoseloff, London

Weissman, R.M. (2001) El Midrash dice. El libro de Bereshit, Génesis., Buenos Aires

Editorial BneiSholem 